\title{
Integration of aqueous (micellar) two-phase systems on the proteins separation
}

\author{
Filipa A. Vicente ${ }^{1 \dagger}$, João H. P. M. Santos ${ }^{1 \dagger}$, Inês M. M. Pereira' ${ }^{1}$ Cátia V. M. Gonçalves ${ }^{2}$, Ana C. R. V. Dias²,
} João A. P. Coutinho ${ }^{1}$ and Sónia P. M. Ventura ${ }^{1 *}$ (i)

\begin{abstract}
A two-step approach combining an aqueous two-phase system (ATPS) and an aqueous micellar two-phase system (AMTPS), both based on the thermo-responsive copolymer Pluronic L-35, is here proposed for the purification of proteins and tested on the sequential separation of three model proteins, cytochrome c, ovalbumin and azocasein. Phase diagrams were established for the ATPS, as well as co-existence curves for the AMTPS. Then, by scanning and choosing the most promising systems, the separation of the three model proteins was performed. The aqueous systems based on Pluronic $\mathrm{L}-35$ and potassium phosphate buffer $(\mathrm{pH}=6.6)$ proved to be the most selective platform to separate the proteins $\left(S_{\text {Azo/Cyt }}=1667 ; S_{\text {Ova/Cyt }}=5.33\right.$ e $\left.S_{\text {Azo/Ova }}=1676\right)$. The consecutive fractionation of these proteins as well as their isolation from the aqueous phases was proposed, envisaging the industrial application of this downstream strategy. The environmental impact of this downstream process was studied, considering the carbon footprint as the final output. The main contribution to the total carbon footprint comes from the ultrafiltration ( 49\%) and the acid precipitation ( 33\%) due to the energy consumption in the centrifugation. The ATPS step contributes to $\sim 17 \%$ while the AMTPS only accounts for $0.30 \%$ of the total carbon footprint.
\end{abstract}

Keywords: Aqueous (micellar) two-phase systems, Downstream process, Thermo-responsive copolymers, Proteins, Carbon footprint

\section{Background}

In the past few years, there has been an increased interest and effort focused the extraction and separation of proteins, not only those produced via fermentation, but also proteins recovered from different raw materials and biomass matrices. Most fermentative processes result in a product that is a complex combination of proteins and other metabolites or cell debris. However, in this protein rich-pool, it is quite difficult to achieve a good separation and purification of the target protein from all the other contaminants. Bioprocesses require efficient purification platforms for the isolation of the desired components and the elimination of the by-products. These are still the main challenge for the industrial applications [1], and responsible for up to $80 \%$ of the production costs [2]. Recently, with the increased attention given to

\footnotetext{
* Correspondence: spventura@ua.pt

${ }^{\dagger}$ Filipa A. Vicente and João H. P. M. Santos contributed equally to this work. ${ }^{1}$ Departamento de Química, CICECO, Universidade de Aveiro, Aveiro, Portugal

Full list of author information is available at the end of the article
}

the valorisation of new products from emergent raw materials and biomass, such as algae [3] and cyanobacteria [4], the development of improved downstream approaches is of high interest and value.

Conventional downstream processes to purify proteins are based on chromatographic techniques, namely size exclusion chromatography, ion exchange chromatography and hydrophobic chromatography [5, 6]. These methods are easy to validate and implement in batch and larger scale, however they are quite expensive. Among the non-chromatographic methods, ultrafiltration $[7,8]$ and precipitation $[9,10]$ appear as the main approaches used in protein separation, though, these methods are ineffective in the separation of similar proteins, since they only act based on protein size and hydrophilicity, respectively. Over the last years, aqueous two-phase systems (ATPS) emerged as an alternative platform for protein separation, considering their intrinsic versatility, in some cases leading to an enhanced purification performance [11]. 
ATPS are a particular type of biphasic system used in liquid-liquid extraction as a primary recovery step for the product isolation and purification by partially separating it from impurities or substrates, hence reducing the subsequent downstream processing volume. One of the most important advantages of ATPS is the high-water content in both phases, which turns the microenvironment of the system more biocompatible for proteins and other biomolecules. This downstream platform is interesting since it can combine several steps into a single operation, namely clarification, extraction, isolation, purification and concentration of the compound [12]. In chemical industry, two-phase systems are employed due to its simplicity, low costs, low viscosity, short phase separation time and easier scale-up [11, 12]. ATPS have been widely applied on the purification and recovery of biological products, such as proteins, genetic material, organelles and bionanoparticles [12]. For that purpose there are some physicochemical properties of the biomolecules (isoelectric point, surface hydrophobicity and molar mass) as well as of the ATPS components [11] ((co) polymers, salts, surfactants and ionic liquids [13]) and process conditions selected (such as the system temperature, or $\mathrm{pH}[6,14])$ that must be taken into account and optimized.

Pluronic triblock copolymers are non-ionic surfactants from the polyoxyethylene alkyl ether family being composed by units of polyethylene glycol (PEG) and polypropylene glycol (PPG). By changing the number of PEG units in the copolymer, its hydrophilicity can be controlled. The copolymers critical micelle concentration (CMC) and surface activity are much more sensitive to temperature than those for the conventional surfactants due to their composition [15], making them more versatile. Among others they are thermo-responsive, being able to form two macroscopic phases when submitted to a temperature above their cloud point, and are commonly known as aqueous micellar two-phase systems (AMTPS) [11]. In 2000, Persson et.al [16]. proposed a copolymerstarch ATPS as part of an integrated process, in which they managed to purify apolipoprotein A-1 from an E. coli fermentation broth and from human plasma.

An integrated platform for the purification of a model protein mixture, composed of cytochrome c, ovalbumin and azocasein, is here proposed. Besides the need to improve the processes efficiency and reduce their cost, there is a growing concern to evaluate their environmental impact. Here, an environmental evaluation of the new two-step approach proposed was carried using the carbon footprint as indicator.

\section{Results and discussion}

Design and characterization of the separation process

The present work reports a novel approach for the separation of proteins. This is divided into two sequential liquid-liquid extraction steps, a first step based in ATPS and a second step based in AMTPS.

\section{Measurement of the ATPS phase diagrams and tie-lines}

The ATPS were characterized through the measurement of the phase diagrams and tie-lines (TLs), aiming at understanding the effect of different inorganic salts and the copolymer nature along with the influence of surfactants used as adjuvants on their formation. The phase diagrams were determined for all the ATPS studied, as depicted in Figs. 1, 2, and 3. All curves were determined using the cloud-point titration method at $25 \pm 1{ }^{\circ} \mathrm{C}$ and atmospheric pressure. The experimental points were correlated using the Merchuk equation [17]. Its parameters (A, B and C) used on the description of the experimental binodal data as well as the experimental data for the phase diagrams are reported in Additional file 1: Tables S1-S4. The experimental TLs, along with their respective length (tie-line length, $T L L s$ ), are reported in Additional file 1: Table S5. The TLL is a numerical indicator of the difference between the compositions of the two phases and it is generally used to correlate trends in the partition of solutes between both phases. The mixtures with total compositions along a specific $T L$ have different mass or volume ratios from those of the two coexisting phases, though the composition of each phase is maintained [18].

Regarding the effect of inorganic salts in the ATPS formation, their aptitude to promote the phase separation was studied for potassium phosphate salts, namely $\mathrm{K}_{2} \mathrm{HPO}_{4}, \mathrm{KH}_{2} \mathrm{PO}_{4}, \mathrm{~K}_{3} \mathrm{PO}_{4}$ and $\mathrm{K}_{2} \mathrm{HPO}_{4} / \mathrm{KH}_{2} \mathrm{PO}_{4}$. The study of inorganic salt nature has been performed on ATPS composed of Pluronic L-35 as the phase former in presence of small amounts of Triton X-100 (circa of 1 wt\%) - Fig. 1. Herein, the ability to promote the two-phase formation follows the order: $\mathrm{K}_{3} \mathrm{PO}_{4}>$ $\mathrm{K}_{2} \mathrm{HPO}_{4} / \mathrm{KH}_{2} \mathrm{PO}_{4} \approx \mathrm{K}_{2} \mathrm{HPO}_{4}>\mathrm{KH}_{2} \mathrm{PO}_{4}$. In general, the potassium phosphate salts with higher salting-out strength exhibit a wider biphasic region. This observation corroborates the qualitative trend on the salt cations ability to induce the salting-out nature of the copolymer, which follows closely the Hofmeister series [19] with $\mathrm{KH}_{2} \mathrm{PO}_{4}$ and $\mathrm{K}_{3} \mathrm{PO}_{4}$ being the weakest and strongest salting-out agents, respectively. Considering the buffer capacity of the potassium phosphate buffer $\left(\mathrm{K}_{2} \mathrm{HPO}_{4} /\right.$ $\mathrm{KH}_{2} \mathrm{PO}_{4}$ ), a very attractive aspect for the proteins separation, along with its larger biphasic region, this system was adopted in the following studies.

The presence of a surfactant as adjuvant was evaluated in terms of its ability to promote the two-phase formation by using small amounts (circa of $1 \mathrm{wt} \%$ ) of two non-ionic surfactants, namely Triton X-114 and Triton $\mathrm{X}-100$, whose characteristics and chemical structure are present in Additional file 1: Table S6. These surfactants 


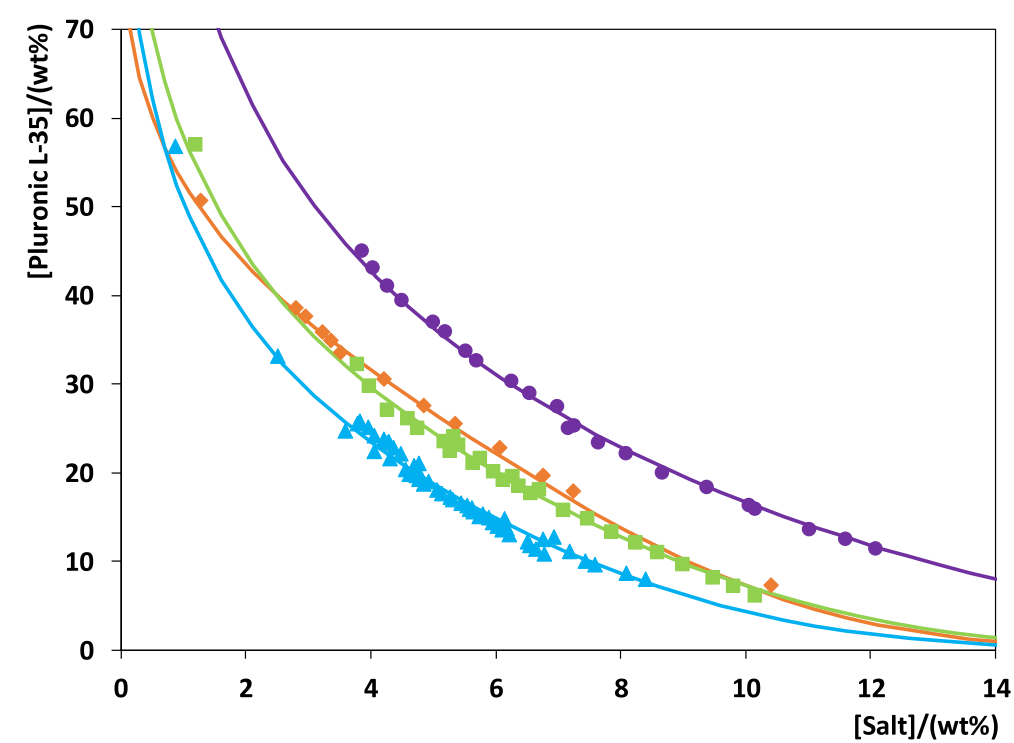

Fig. 1 Phase diagrams of the copolymer Pluronic L-35 and inorganic salts - (\) $\mathrm{K}_{2} \mathrm{HPO}_{4} ;(\boldsymbol{\bullet}) \mathrm{KH}_{2} \mathrm{PO}_{4} ;(\mathbf{N}) ; \mathrm{K}_{3} \mathrm{PO}_{4}$ and $(\square) \mathrm{K}_{2} \mathrm{HPO}_{4} / \mathrm{KH}_{2} \mathrm{PO}$; at $25^{\circ} \mathrm{C}$. The lines represent the Merchuk fit through Eq. 1

possess a similar chemical structure, varying only in the number of ethoxylate groups forming the surfactant's crown and thus, its hydrophilicity (cf. the hydrophiliclipophilic balance (HLB) of the surfactants is presented in Additional file 1: Table S6). The surfactants' influence was analysed in a Pluronic L-35 + potassium phosphate buffer-based ATPS and compared with the conventional system (without any adjuvant present) - Fig. 2. The results show that the use of these co-surfactants does not significantly affects the binodal curves, and thus the phases separation in this system
The copolymer nature (normal versus reverse) and composition (weight percentage of PEG units, cf. Additional file 1: Table S6) were two other aspects explored on the phase diagrams. Three different copolymers were selected, namely Pluronics 17R4, 10R5 and L-35 and studied using a pseudo-ternary system composed of potassium phosphate buffer $(\mathrm{pH}=6.6)$. The respective phase diagrams are present in Fig. 3, where a tendency can clearly be established, considering their capacity to form two phases, as Pluronic 17R4 > Pluronic 10R5 > Pluronic L-35.

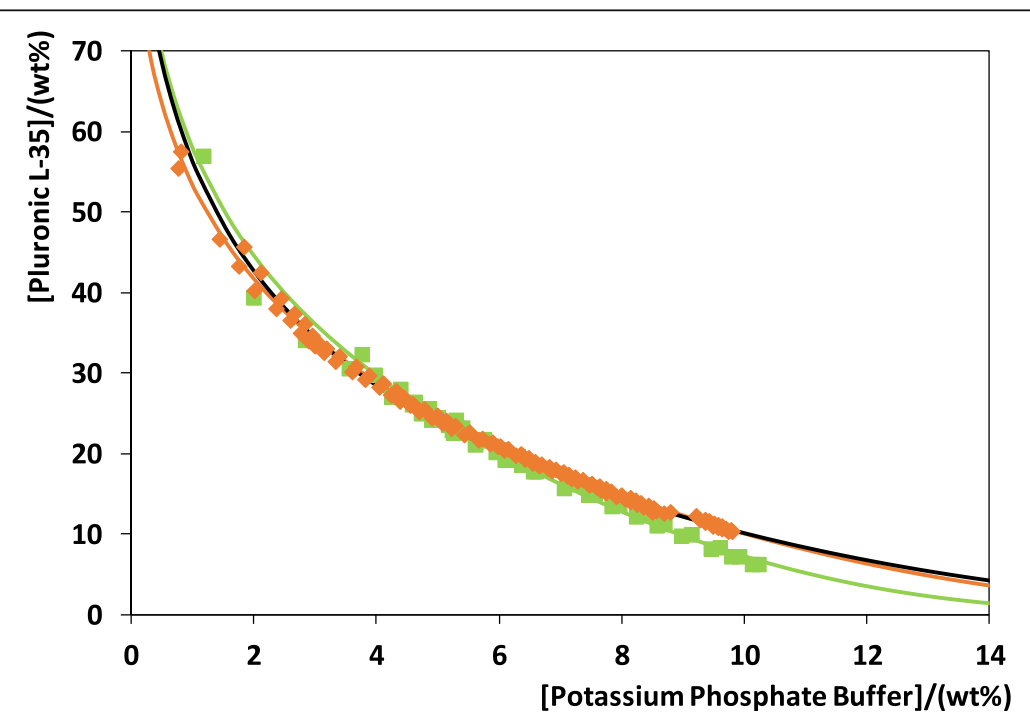

Fig. 2 Phase diagrams of the copolymer Pluronic L-35 + potassium phosphate buffer $(\mathrm{pH}=6.6)$, without the addition of surfactant ( $\mathbf{C}$ ); and with the addition of $1 \mathrm{wt} \%$ of Triton X-100 ( $\square$ ); and Triton X-114 ( $\$)$, at $25^{\circ} \mathrm{C}$. The lines represent the Merchuk fit through Eq.1 


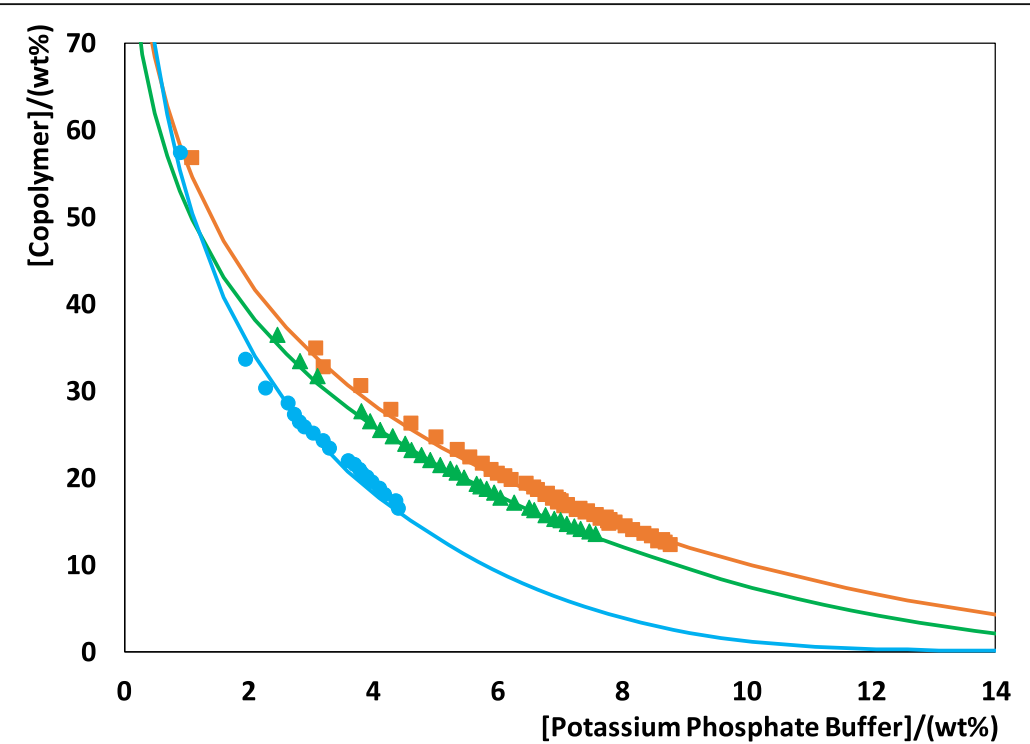

Fig. 3 Phase diagrams obtained for the copolymers: Pluronic 17R4 (@); Pluronic 10R5 (へ); and Pluronic L-35 ( $\square$ ) + potassium phosphate buffer $(\mathrm{pH}=6.6)$, at $25^{\circ} \mathrm{C}$. The lines represent the Merchuk fit through Eq.1

Herein, Pluronic 17R4 holds the wider biphasic region, due to its more hydrophobic nature, considering the $60 \mathrm{wt} \%$ of PPG in its composition compared with the $50 \mathrm{wt} \%$ in the remaining copolymers. In contrast, Pluronic L-35 displays the narrowest biphasic region, though with only a small difference for Pluronic 10R5. This difference is a result of the copolymer structural rearrangement, i.e. Pluronic L-35 is composed of repetitive units of PEG-PPG-PEG, while Pluronic 10R5 presents sequences of PPG-PEG-PPG. Therefore, the normal copolymer evidences a higher hydrophilicity owing to the two PEG units, resulting in a lower ability to form the two-phases.

\section{Measurement of the AMTPS coexisting curves}

As thermo-responsive copolymers, these systems can be induced to form two-phases using temperature as the driving force. The cloud points were determined, and the phase diagrams are presented in Fig. 4. These results show that the copolymer nature and composition display a major effect on the AMTPS formation, namely upon the cloud points. Once again, the ability of the

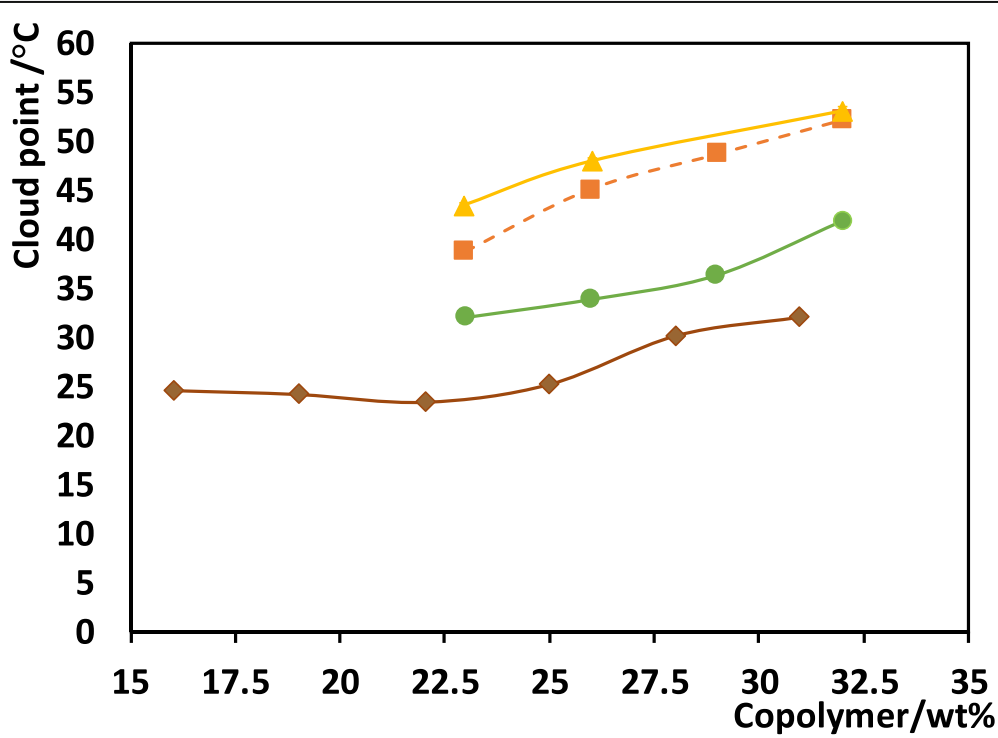

Fig. 4 Coexistence curves for the ternary systems with potassium phosphate buffer + water + Pluronic 17R4 ( $\$$ ); Pluronic 10R5 (๑); and Pluronic L-35 ( $($ ) ; and for the quaternary system composed of potassium phosphate buffer + Pluronic L-35 + water + 1 wt\% of Triton X-114 (- - --) 
copolymers to form the biphasic region follows the tendency of Pluronic 14R4 > Pluronic 10R5 > Pluronic L-35. The main difference is that now, there is the formation of an AMTPS instead of a simpler ATPS, which means that the phase separation occurs due to the micelles coalescence in one phase and is not a result of the copolymer being salted-out by the salt. Herein, there is a complex balance of distinct interactions (electrostatic interactions, hydrophobic associations, hydrogen bonds and van der Waals forces), which in turn affects both solute-solute and solute-solvent interactions [20]. Moreover, it is well known that the addition of a co-surfactant can, not only reduce the system cloud points, but also improve the system extractive performance [20,21]. This is the best option in terms of the cloud point extraction of labile proteins, and thus, the quaternary system composed of Pluronic L-35 + potassium phosphate buffer (+ water) + Triton X-114 was also characterized and depicted in Fig. 4 (dashed line and square symbol).

Through these results, it is visible a slight reduction of the cloud point temperatures of this system in comparison with the pseudo-ternary system composed of Pluronic L-35, but in absence of Triton X-114 as co-surfactant. Since both Pluronic L-35 and Triton $\mathrm{X}-114$ are non-ionic surfactants above their CMC, non-ionic mixed micelles are formed. Nevertheless, it seems that there is a dominance of the copolymer in the aggregate's formation, since it is present in higher concentration.

\section{Optimization of the proteins partition applying ATPS and AMTPS}

Once the phase diagrams had been characterized, a mixture point was selected, considering two criteria, the water content, and an appropriate temperature, above the system cloud point, but not too high to maintain the proteins thermal stability. As previously mentioned, cytochrome c, azocasein and ovalbumin were the model proteins selected (cf. properties in Additional file 1: Table S7). The ternary system composed of Pluronic 17R4 was not used due to experimental restrictions imposed by its very low cloud point $\left(25^{\circ} \mathrm{C}\right)$.

Thus, the systems studied in the partition of proteins were the ones constituted by Pluronic L-35 and Pluronic 10R5 and the quaternary system composed of Pluronic L-35 + potassium phosphate buffer + water + Triton $\mathrm{X}-114$. The ATPS and AMTPS prepared to perform the partition tests are exemplified by the case of Pluronic L-35 as presented in Additional file 1: Figure S1.

The recovery and partition coefficient data obtained for each model protein in both (top and bottom) phases of the ATPS and AMTPS were determined, and the results presented in Figs. 5, 6, Additional file 1: Figure S2 and S3. From the Recovery results displayed in Figs. 5 and 6 and corroborated by the partition coefficient data (Additional file 1: Figures S2 and S3), it is clear the cytochrome c (red bars) preferential partition to the bottom/ salt-rich phase whereas azocasein (blue bars) was completely recovered in the top/copolymer-rich phase. Contrarily, the ovalbumin (green bars) partition was found to be dependent on the system, since for Pluronic L-35-based AMTPS, ovalbumin is mainly recovered in the top phase, while for Pluronic 10R5, this protein partitions preferably for the bottom-phase of the ATPS.

The cytochrome $\mathrm{c}$ preferential partition to the salt-rich phase can be improved by the proper choice of the copolymer, being this partition more pronounced for Pluronic 10R5 (\%Rec Bottom = $95 \pm 5 \%$ ). It is also clear that electrostatic interactions between proteins and the buffer are not the only parameter influencing the proteins' partition behaviour since both cytochrome $\mathrm{c}$ and ovalbumin partition varies with the copolymer applied. For instance, when the normal is replaced by the reverse Pluronic, the ovalbumin partition tendency completely changed with around $60 \%$ of this protein being concentrated not in the polymeric phase but in the salt-rich phase. This leads to the conclusion that some more specific interactions between the copolymers and ovalbumin should be occurring and dictating its partition. Likewise, cytochrome c recovery is also improved with this copolymer replacement, suggesting that the more hydrophobic character of Pluronic 10R5 might be forcing more cytochrome $\mathrm{c}$ to migrate towards the more hydrophilic phase.

Regarding the presence of Triton X-114 as co-surfactant, it was found that the ovalbumin recovery is enhanced by $20 \%$ to the copolymer-rich phase. This reinforces the notion that some specific interactions between the system phase formers and the proteins contribute to their partition.

To further elucidate the ability of these systems to separate the proteins, the ATPS selectivity was also determined. As expected, higher selectivity values were obtained for the Pluronic L-35 in the partition of ovalbumin and cytochrome c. Even though the presence of Triton X-114 affects the partition of proteins, a negligible effect is observed when the proteins selectivity (especially $\mathrm{S}_{\mathrm{Ova} / \text { Cyt c }}$ ) is investigated. Nevertheless, outstanding selectivity values were obtained for the partition of azocasein and cytochrome $\mathrm{c}$ in all the studied systems $(\mathrm{S}>1250)$.

Sequentially, the ATPS top phase was submitted to a temperature above the cloud point of each system and allowed it to separate into two macroscopic phases, aiming at separating ovalbumin and azocasein in the end (Fig. 6). Once again, azocasein migrated completely towards the top/surfactant-rich phase while ovalbumin partitioned mostly to the bottom/surfactant-poor phase. The ability to fractionate both model proteins in the AMTPS is described by the trend: Pluronic 10R5< 


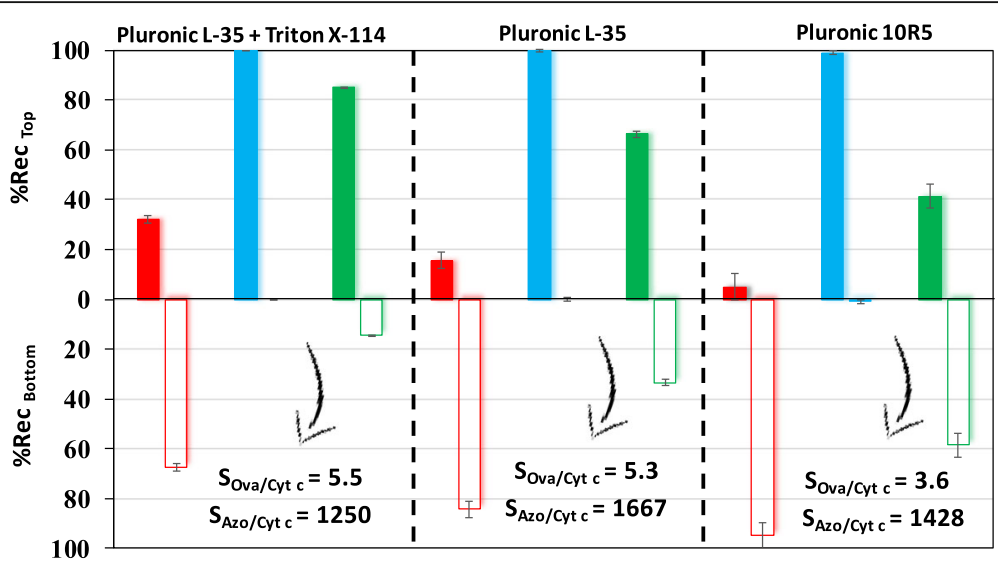

Fig. 5 Recovery data obtained for the three proteins regarding top/copolymer-rich phase (\%Rec Top) and bottom/salt-rich phase (\%Rec Bottom)

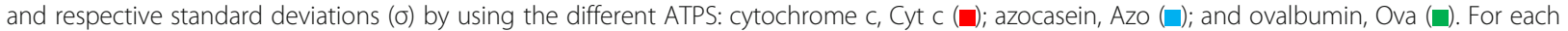
system studied the selectivity results are reported

Pluronic L-35 + 1 wt\% Triton X-114 < Pluronic L-35. The differential partition between the two proteins can be explained by their molecular weights and hydrophobic/ hydrophilic character [21, 22]. The smallest and more hydrophobic protein, in this case azocasein, is recovered inside the micelles, while ovalbumin, due to its higher molecular weight and more hydrophilic character, is excluded to the most hydrophilic phase, the surfactantpoor phase. As far as the pseudo-ternary and quaternary systems with Pluronic L-35 are concerned, it can be assumed that the micelle complexity of the quaternary AMTPS hinders the partition of ovalbumin towards the surfactant-rich phase. Therefore, the addition of a co-surfactant is not so selective as it was in the first separation step, probably by the nature of the mixed micelles created [21]. Taking these results into account, the system with Pluronic L-35 was identified as the most selective system for the two fractionation steps.

\section{Sequential fractionation of the protein mixture}

The separation of the three proteins present in a single mixture was performed for the most selective system composed of Pluronic L-35 + potassium phosphate buffer + water. The isolation of each protein from the phase formers was a step also investigated in this work and corroborated by distinct techniques. Herein, two different parameters were considered to analyse the proteins purification owing to the use of a complex protein mixture, namely the proteins recovery $\left(R_{x}\right)$ in each phase and their purity $\left(\mathrm{P}_{\mathrm{x}}\right)$. This data is presented in Fig. 7 and Additional file 1: Figure S4. As expected, the protein partition of ovalbumin, azocasein and cytochrome c maintained almost the same partition profile as previously observed for each protein when individually tested (section 2.2 of this work). Herein, cytochrome c was completely recovered in the salt-rich phase of the ATPS $\left(\mathrm{R}_{\text {Cyt }} \mathrm{c}=100 \%\right.$ and $\left.\mathrm{P}_{\mathrm{Cyt}} \quad \mathrm{c}=14 \%\right)$, which was an

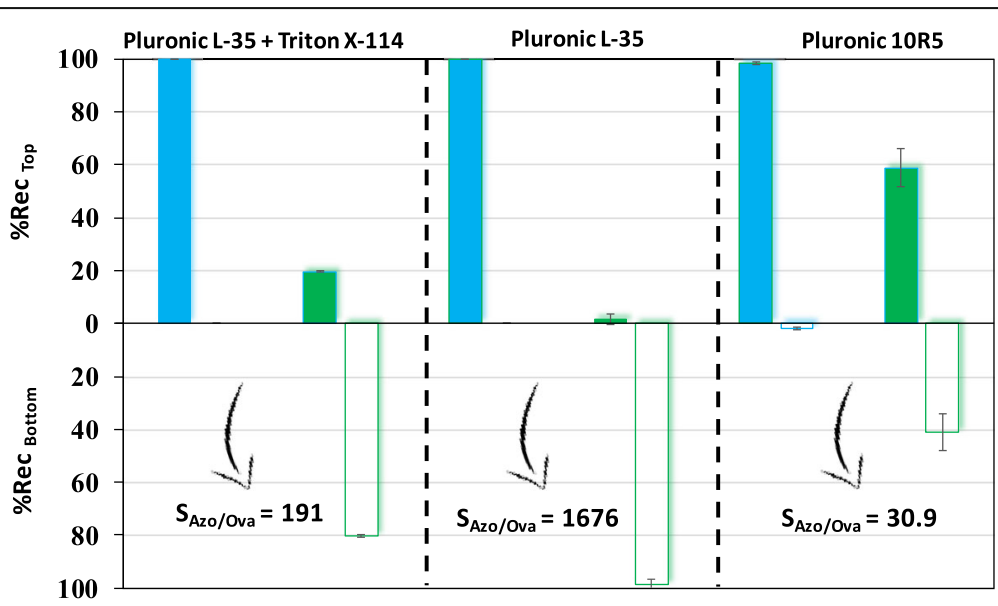

Fig. 6 Recovery values obtained for the surfactant-rich phase (\%Rec Top) and surfactant-poor phase (\%Rec Bottom), with the respective standard deviations $(\sigma)$ by applying AMTPS to separate azocasein $(\square)$; and ovalbumin $(\square)$. For each system studied the selectivity results are presented 


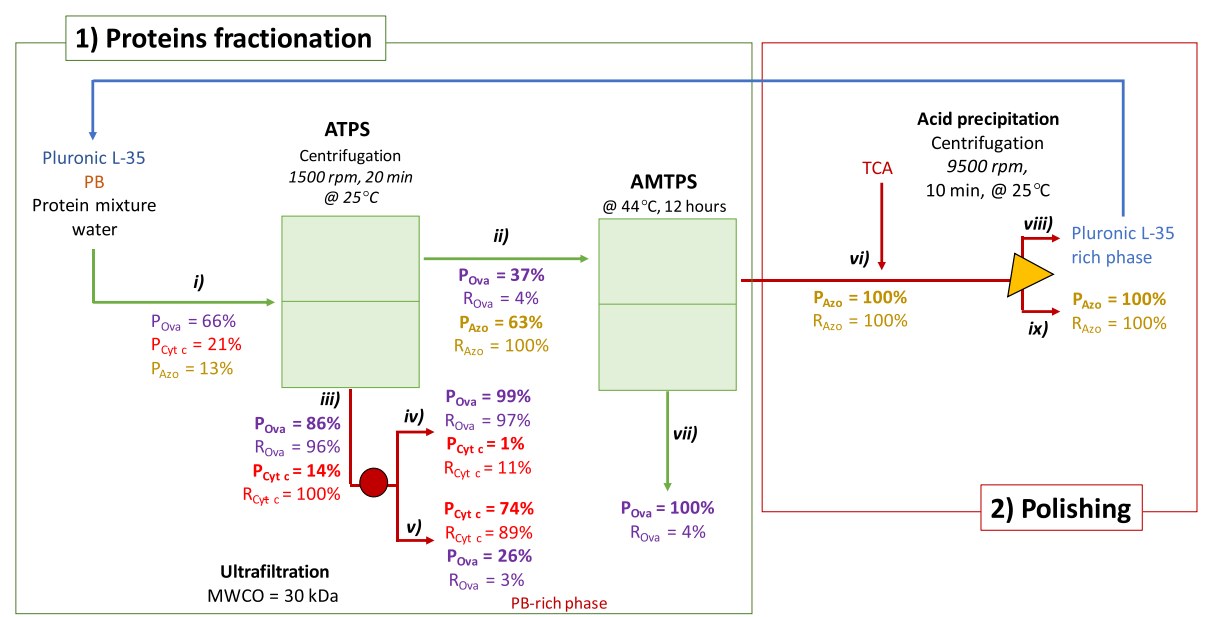

Fig. 7 Diagram of the integrated process to selectively separate cytochrome c (Cyt c), ovalbumin (Ova) and azocasein (Azo). The proposed strategy includes two steps of purification using, respectively, ATPS and AMTPS based on Pluronic L-35 and potassium phosphate buffer - PB (pH $=6.6)$. The purity $\left(P_{x}\right)$ and recovery $\left(R_{x}\right)$ of each step is provided in the present diagram. An ultrafiltration was applied to improve the separation of Cyt $c$ and Ova and an acid precipitation was applied to isolate the Azo from Pluronic L35. The potassium phosphate buffer was maintained in the Azo-rich phase as a stabilizing solution

improvement compared to the results previously obtained for each protein tested individually. However, ovalbumin partitioned almost completely to the salt-rich phase contrarily to the expected $\left(\mathrm{R}_{\mathrm{Ova}}=96 \%\right.$ and $\mathrm{P}_{\mathrm{Ova}}=$ $86 \%$ ), being the remaining concentration separated from azocasein in the second fractionation step, applying the AMTPS. In this case, azocasein was completely recovered in the surfactant-rich phase $\left(\mathrm{R}_{\mathrm{Azo}}=100 \%\right.$ and $\mathrm{P}_{\mathrm{Azo}}$ $=100 \%$ ), whereas the ovalbumin still present in the system was totally concentrated in the surfactant-poor phase $\left(\mathrm{R}_{\text {Ova }}=4 \%\right.$ and $\left.\mathrm{P}_{\text {Ova }}=100 \%\right)$. In the end, an ultrafiltration step was applied to isolate cytochrome $\mathrm{c}$ and ovalbumin, obtaining a cytochrome c recovery of $89 \%$ with a $74 \%$ purity and recovering $97 \%$ of an almost pure (99\%) ovalbumin. Aiming at the industrial potential of the integrated process developed, an isolation step was considered in this integrated process enabling the reuse of copolymer for additional cycles of purification. For this step, an acid precipitation of Azo was carried using TCA (0.1 M at $\mathrm{pH} 3-4)$ to promote the azocasein isolation from Pluronic L-35, as represented in Additional file 1: Figure S5. After Azo precipitation, the pellet was microfuged at maximum speed and the supernatant was discharged, being applied a solution of $\mathrm{NaOH}(0.1 \mathrm{M})$ to further dissolve the precipitated protein. Both the azocasein isolation and copolymer recovery were confirmed through ${ }^{1} \mathrm{H}$ NMR and FTIR, as shown in Additional file 1: Figures S6 and S7, respectively. The NMR data seems identical before and after the polishing step, Additional file 1: Figure S6, however, the FT-IR spectra were different. In Additional file 1: Figure S7, the main differences between the aqueous copolymer solution (black line) and the supernatant (red line) presenting essentially
Pluronic L-35 correspond to the amount of water present in the solutions (cf. $1625 \mathrm{~cm}^{-1}$ : water $\mathrm{H}-\mathrm{O}-\mathrm{H}$ bend and $3400-3200 \mathrm{~cm}^{-1}$ : water $\mathrm{O}-\mathrm{H}$ stretch). The potassium phosphate buffer was not recovered since it is a common media used to stabilize proteins.

Overall, high purities (>74\%) were obtained for the four distinct polished streams: $i v), v$ ), vii) and $i x$ ), as presented in Fig. 7. It should be stressed that circa of $5 \mathrm{wt} \%$ of Pluronic L-35 is still present in stream ix); yet, this copolymer concentration is at an acceptable concentration approved by FDA [23].

Summing up, a high-performance separation process was here developed by the sequential application of ATPS and AMTPS to separate ovalbumin (maximum yield and purity of 97 and 99\%, respectively), azocasein (maximum yield and purity of $100 \%$ ) and cytochrome c (maximum yield and purity of 89 and 74\%, respectively).

\section{Environmental assessment}

Figure 8 shows the results of the carbon footprint of the novel purification platform of proteins complex matrices per $1 \mathrm{~kg}$ of aqueous system. The total carbon footprint is equal to $117 \mathrm{~kg} \mathrm{CO} \mathrm{CO}_{2}$. The contribution of the fractionation process $\left(79 \mathrm{~kg} \mathrm{CO} \mathrm{CO}_{2}\right.$ eq.), which includes the ATPS, AMTPS and ultrafiltration steps, represents $\sim 67 \%$ of the total carbon footprint, is dominated by the ultrafiltration step $(\sim 49 \%)$. The proteins isolation process contributes with $39 \mathrm{~kg} \mathrm{CO}$ eq. This process encompasses the acid precipitation step, representing $\sim 33 \%$ of the total carbon footprint. The main contribution to the carbon footprint comes from the electricity consumption, more precisely, the electricity consumption in the centrifugation processes 


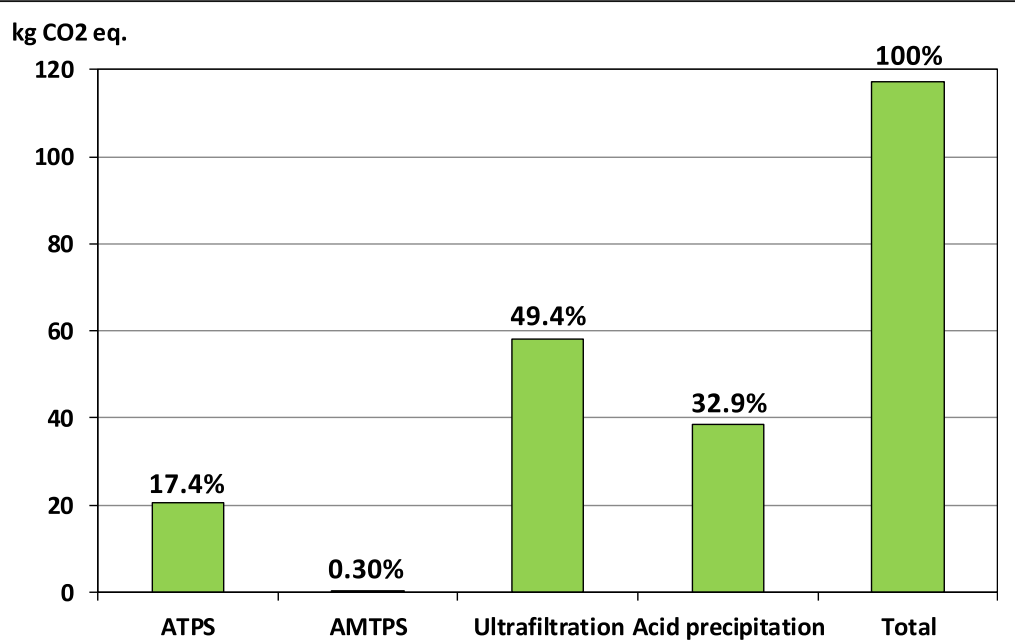

Fig. 8 Carbon footprint for the two scenarios proposed for $1 \mathrm{~kg}$ of aqueous system

of the ultrafiltration and acid precipitation steps (representing a contribution of 99.6 and $99.9 \%$ of the carbon footprint for each step, respectively). The carbon footprint of the ATPS step is also dominated by electricity consumption, mainly by the centrifuge, contributing to $95 \%$ of the carbon footprint. However, it should be noted that the energy consumption of some equipment should be reviewed in view of the system industrial implementation.

\section{Conclusions}

An integrated purification platform composed of ATPS and AMTPS was here proposed for the fractionation of different biomolecules present in complex matrices. Both the ATPS and AMTPS were first characterized, and then applied in the fractionation of a mixture of three model proteins, namely cytochrome c, azocasein and ovalbumin. The results herein obtained showed that the ternary system composed of Pluronic L-35 (23wt\%) + potassium phosphate buffer (6 $\mathrm{wt} \%)$ was the most selective system as proved by the selectivity values achieved: $\mathrm{S}_{\mathrm{Azo} / \text { Cyt }}=1667, \mathrm{~S}_{\mathrm{Ova} / \mathrm{Cyt}}$ $=5.33$ and $S_{\text {Azo/Ova }}=1676$. The combination of these two liquid-liquid extraction units emerged as an attractive platform to improve the extraction and purification of proteins, with a final fractionation of cytochrome $\mathrm{c}$ and ovalbumin being achieved through ultrafiltration and an acid precipitation carried out to isolate azocasein from the copolymer. Finally, the carbon footprint was evaluated to better understand the environmental impacts of this new protein purification process. The main contribution to the total carbon footprint of the system comes from the ultrafiltration $(\sim 49 \%)$ and acid precipitation $(\sim 33 \%)$ steps mainly due to their energy consumption.

\section{Material and methods Materials}

Three phosphate-based salts were used, namely monopotassium phosphate $\left(\mathrm{K}_{2} \mathrm{HPO}_{4}\right)$ acquired on Panreac (99 wt\% purity), dipotassium phosphate $\left(\mathrm{KH}_{2} \mathrm{PO}_{4}\right)$ obtained from Sigma ( $99.5 \mathrm{wt} \%$ purity) and tripotassium phosphate $\left(\mathrm{K}_{3} \mathrm{PO}_{4}\right)$ attained from Acros Organic (97 wt $\%$ purify). A phosphate-buffer solution $\left(\mathrm{K}_{2} \mathrm{HPO}_{4} /\right.$ $\mathrm{KH}_{2} \mathrm{PO}_{4}$ ) was also used at $\mathrm{pH}=6.6$. The copolymers employed in this work were Pluronic L-35, Pluronic 10R5 and Pluronic 17R4, all acquired at Sigma-Aldrich, being their characteristics and chemical structure presented in Additional file 1: Table S6. As co-surfactants, Triton X-114 and Triton X-100 (purity > $95 \mathrm{wt} \%$ ) purchased from Acros Organic, were tested (cf. characteristics and chemical structure presented in Additional file 1: Table S6). Cytochrome c (purity >95 wt\%) from equine heart and azocasein ( $99 \mathrm{wt} \%$ purity) were acquired from Sigma-Aldrich, whereas albumin from hen egg white (97 wt\% purity) was supplied by Fluka, BioChemika.

\section{Measurement of phase diagrams and tie-lines for ATPS}

The binodal curves of the ATPS with different compositions were determined using the cloud-point titration method [24] at $25( \pm 1)^{\circ} \mathrm{C}$, at atmospheric pressure. This technology is based on the dropwise addition of a salt solution to a polymer aqueous solution, both with known concentrations, until the mixture becomes turbid (representing the biphasic system). Then, a known mass of water was added to clear the solution (corresponding to the monophasic system). This procedure was repeated to obtain enough data for the design of the respective binodal curves. The phase diagram data were correlated using the Merchuk equation [17], as described in Eq.1: 


$$
[\text { Copolymer }]=A \times \exp \left[\left(B[\text { Salt }]^{0.5}\right)-\left(C X^{3}\right)\right]
$$

where [Copolymer] and [Salt] are respectively the copolymer and inorganic salt weight percentages (wt\%). Three different studies were attained for the phase diagrams design: the inorganic salt type, the copolymer type and the presence of adjuvants (Triton X-100 and Triton $\mathrm{X}$-114). In this sense, for the inorganic salt type study, four salts were used: $\mathrm{K}_{2} \mathrm{HPO}_{4}, \mathrm{KH}_{2} \mathrm{PO}_{4}, \mathrm{~K}_{3} \mathrm{PO}_{4}$ and $\mathrm{K}_{2} \mathrm{HPO}_{4} / \mathrm{KH}_{2} \mathrm{PO}_{4}$, being the Pluronic L-35 and Triton $\mathrm{X}-100$ maintained constant. For the second study, different copolymers (Pluronic L-35, Pluronic 10R5, and Pluronic 17R4) were studied while the potassium phosphate buffer $\left(\mathrm{K}_{2} \mathrm{HPO}_{4} / \mathrm{KH}_{2} \mathrm{PO}_{4}, \mathrm{pH}=6.6\right)$ was kept constant. Finally, the impact of small amounts of Triton X-114 (1 wt\%) was studied for the system constituted by Pluronic $\mathrm{L}-35$ and the potassium phosphate buffer $(\mathrm{pH}=6.6)$.

The TLs were determined by the gravimetric method originally proposed by Merchuk et al. [17], for the extraction points presented in Additional file 1: Table S8, to calculate the composition of the two-phases in equilibrium. The compositions of copolymer and salt in the top and bottom phases were obtained as well as the TLL [25], being the data presented in Additional file 1: Figure S8 and Table S8.

\section{Measurement of the AMTPS cloud point curves}

The AMTPS cloud point curves were carried out by the cloud point method [26]. Herein, the AMTPS corresponds to the ATPS top phase, which was composed of potassium phosphate buffer $\left(\mathrm{K}_{2} \mathrm{HPO}_{4} / \mathrm{KH}_{2} \mathrm{PO}_{4}\right)$ at $\mathrm{pH}$ $=6.6$ or water and a different copolymer (Pluronic L-35, Pluronic 10R5 or Pluronic 17R4). For the AMTPS using Triton X-114 as adjuvant, the ATPS top phase also displayed this component. Basically, this procedure consists on a visual identification, while raising the temperature, of the point at which a mixture with known compositions becomes turbid (biphasic system), indicating the system cloud point. The experimental curves were obtained by plotting the cloud point versus the copolymer mass concentration. These curves represent the boundary between the conditions at which the system presents a single phase (below/outside the curve) or two macroscopic phases (above/inside the curve). Once the cloud point curves were measured, a mixture point for each system in the biphasic region on both the ATPS and AMTPS was selected, at the lowest possible polymer concentration and temperature. The experimental mixture in the ATPS was selected with $23 \mathrm{wt} \%$ of copolymer and $6 \mathrm{wt} \%$ of potassium phosphate buffer $(\mathrm{pH}=6.6)$, for a final volume of $5 \mathrm{~mL}$. It should be noted that the copolymers concentration in the cloud point curves are not identical for all the studied systems since for
Pluronics $10 \mathrm{R} 5$ and L-35, there is not a biphasic region for concentrations lower than $22 \mathrm{wt} \%$.

\section{ATPS coupled with AMTPS to separate model proteins - Single protein purification}

Two pseudo-ternary systems composed of $23 \mathrm{wt} \%$ of Pluronic $10 \mathrm{R} 5$ or L-35 + $6 \mathrm{wt} \%$ of potassium phosphate buffer + $71 \mathrm{wt} \%$ of proteins solution and one quaternary system composed of $23 \mathrm{wt} \%$ of Pluronic L-35 $+6 \mathrm{wt} \%$ of potassium phosphate buffer $+1 \mathrm{wt} \%$ of Triton X-114 $+70 \mathrm{wt} \%$ of proteins solution were studied as the purification platforms for three model proteins: cytochrome c $\left(0.5 \mathrm{~g} . \mathrm{L}^{-1}\right)$, azocasein $\left(0.3\right.$ g.L $\left.\mathrm{L}^{-1}\right)$ and ovalbumin (1.59 g... $\left.\mathrm{L}^{-1}\right)$.

On the first step of purification (ATPS), the systems were homogenised for $2 \mathrm{~h}$ at $25^{\circ} \mathrm{C}$ and then these were centrifuged for $10 \mathrm{~min}$, at $25^{\circ} \mathrm{C}$, and $251.55 \mathrm{~g}$. These conditions allow the two phases formation and equilibrium, after which both phases were collected, their volumes and weights determined, and the proteins quantified by UV-Vis spectroscopy, as described below. For the second step of purification, the top/copolymer-rich-phase was used to the AMTPS formation, being the systems composed of Pluronic 10R5, Pluronic L-35 and Pluronic L-35 + Triton X-114 left at $39{ }^{\circ} \mathrm{C}, 44{ }^{\circ} \mathrm{C}$ and $40^{\circ} \mathrm{C}$ overnight, respectively. Both phases were then collected, their volumes and weights determined, and the proteins quantified by UV-Vis spectroscopy, at a wavelength of $280 \mathrm{~nm}$ for ovalbumin, and $409 \mathrm{~nm}$ for cytochrome c. Azocasein has three characteristic peaks, namely at $215 \mathrm{~nm}, 342 \mathrm{~nm}$, and $440 \mathrm{~nm}$. However, in this work the wavelength of $342 \mathrm{~nm}$ was selected since it represents the maximum absorbance experimentally found. Calibration curves were performed for each model protein. The analytical quantification was performed at least in triplicate, and to prevent possible interferences, blanks were routinely applied. For both steps of purification (ATPS and AMTPS), several parameters were determined. The partition coefficient $(K)$ for each model protein was calculated as the ratio between the equilibrium concentrations of the protein in the top phase $\left([\operatorname{Prot}]_{\mathrm{T}}\right)$ and the protein in the bottom phase $\left([\operatorname{Prot}]_{\mathrm{B}}\right)$. To facilitate the analysis, the $\mathrm{K}$ results were normalized through their logarithmic function, as described by Eq.2:

$$
\log (K)=\log \left(\frac{[\text { Prot }]_{\mathrm{T}}}{\left[\text { Prot }_{\mathrm{B}}\right.}\right)
$$

The recovery parameter of each protein towards the top (\%Rec Top) and the bottom (\%Rec Bottom) phases was determined by the ratio among the protein mass on top or bottom phases, respectively, and the initial protein mass applied in the system (Eqs. 3 and 4): 


$$
\begin{aligned}
& \text { \%Rec Top }=\frac{\mathrm{V}_{\mathrm{T}}[\text { Prot }]_{\mathrm{T}}}{\mathrm{V}_{\mathrm{T}}[\text { Prot }]_{\mathrm{T}}+\mathrm{V}_{\mathrm{B}}[\operatorname{Prot}]_{\mathrm{B}}} \times 100 \\
& \% \text { Rec Bottom }=\frac{\mathrm{V}_{\mathrm{B}}[\operatorname{Prot}]_{\mathrm{B}}}{\mathrm{V}_{\mathrm{T}}[\operatorname{Prot}]_{\mathrm{T}}+\mathrm{V}_{\mathrm{B}}[\text { Prot }]_{\mathrm{B}}} \times 100
\end{aligned}
$$

Since the main intention was to measure the selective partition of the proteins (e.g. protein A and protein B), the selectivity $(S)$ parameter was analysed through Eq. 5:

$$
S=\frac{K_{\text {Prot A }}}{K_{\text {Prot B }}}
$$

Integrated ATPS and AMTPS - complex purification mixture In order to mimic a real system, the three model proteins were simultaneously separated. The most selective integrated system identified, i.e. $23 \mathrm{wt} \%$ Pluronic L $35+$ $6 \mathrm{wt} \%$ potassium phosphate buffer $(\mathrm{pH}=6.6)$ ATPS + AMTPS, was applied for the separation of the proteins from the complex mixture.

The quantification of the proteins was performed using size exclusion chromatography (SEC-FPLC). The top and bottom phases upon separation were injected into an $\mathrm{AKTA}^{\mathrm{sm}}$ purifier system (GE Healthcare) size exclusion chromatographer equipped with a Superdex 200 Increase 10/300 GL chromatographic column prepacked with crosslinked agarose-dextran high resolution resin (GE Healthcare) to quantify the three model proteins. Moreover, through these measurements, the purity and purification yield (\%) were also calculated. The column was equilibrated with $0.01 \mathrm{M}$ of potassium phosphate buffer $(0.14 \mathrm{M} \mathrm{NaCl}, \mathrm{pH}=7.4)$ and eluted with the same buffer at the flow of $0.75 \mathrm{~mL} \cdot \mathrm{min}^{-1}$. The quantification of each proteins was carried out at $280 \mathrm{~nm}$ by FPLC/UV size-exclusion method. The purification performance of the integrated process was evaluated based on the recovery yield $\left(R_{x} \%\right)$ and purity $\left(P_{x} \%\right)$ for the three proteins as it can be seen at Eqs. 6 and 7 .

$$
\begin{aligned}
& R_{x}(\%)=\frac{m\left(\text { Protein }_{\text {purified fraction }}\right)}{m\left(\text { Protein }_{\text {initial }}\right)} \times 100 \\
& \mathrm{P}_{x}(\%)=\mathrm{wt} \text { Protein }_{x}
\end{aligned}
$$

The recovery yield was calculated by dividing the protein weight in the purified fraction by the initial protein weight (before purification). The purity was calculated by the weight percentage of the desirable protein (either Ova, Cyt c, or Azo) present in the purified fraction.

\section{Isolation of model proteins}

The polishing step was performed for the purified protein phases envisioning the industrial applicability of this integrated approach. The acid precipitation of azocasein was performed from the top phase of AMTPS, using 0.1
$\mathrm{M}$ of trichloroacetic acid (TCA), being the pellet dissolved in $0.1 \mathrm{M}$ of $\mathrm{NaOH}$ (Additional file 1: Figure S5). The copolymer recovery through azocasein precipitation was also confirmed by ${ }^{1} \mathrm{H}$ NMR and ATR-FTIR. The recovery of both cytochrome $\mathrm{c}$ and ovalbumin in the bottom phase of ATPS was achieved through ultrafiltration using a $30 \mathrm{kDa}$ cut-off membrane, through Amicon Ultra-15 Centrifugal Filter Units.

\section{Environmental assessment}

The environmental evaluation of the downstream process developed in this work, was carried by the estimation of its carbon footprint for the most performant separation system [Pluronic L-35 triblock + potassium phosphate buffer $\left.\left(\mathrm{K}_{2} \mathrm{HPO}_{4} / \mathrm{KH}_{2} \mathrm{PO}_{4}\right)\right]$. The analysis of the carbon footprint was done considering the application of both (i) ATPS and (ii) AMTPS platforms, the proteins fractionation using ultrafiltration (iii) as well as for the polishing step using acid precipitation (iv). The carbon footprint is the sum of greenhouse gas (GHG) emissions, associated with the system tested, expressed as mass of carbon dioxide equivalent $\left(\mathrm{CO}_{2}\right.$ eq. $)$ from a life cycle perspective.

The production of all the solvents (potassium phosphate buffer, Pluronic L-35 triblock copolymer, TCA, NaOH, distilled water), and the electricity consumed during the operation of the equipment was included in this assessment. Data on the amounts of solvents, distilled water and equipment operating time were obtained during the experiment, while equipment power was taken from equipment catalogues (Additional file 1: Table S8). Data on GHG emissions from the production of all solvents and electricity were sourced from Ecoinvent database version 3.4, being presented in Additional file 1: Table S9 [27]. The GHG emissions for the production of distilled water were calculated based on GHG emissions from tap water production [28] and GHG emissions from electricity consumption during the distillation process. The carbon footprint was calculated for $1 \mathrm{~kg}$ of the aqueous system.

\section{Additional file}

Additional file 1: Supplementary Tables and Figures [29-35]. (DOCX 2089 kb)

\section{Abbreviations}

AMTPS: Aqueous micellar two-phase systems; ATPS: Aqueous two-phase systems; Azo: Azocasein; CMC: Critical micelle concentration; Cyt c: Cytochrome c; GHG: Greenhouse gas; K: Partition coefficient; Ova: Ovalbumin;

PEG: Polyethylene glycol; PPG: Polypropylene glycol; Px: Purity; $R_{x}$ : Recovery; S: Selectivity; TCA: Trichloroacetic acid; TL: Tie-line; TLL: Tie-line length

\section{Acknowledgements}

This work was developed within the scope of the project CICECO-Aveiro Institute of Materials, POCI-01-0145-FEDER-007679 (FCT Ref. UID/CTM/50011/ 2013), and CESAM, POCI-01-0145-FEDER-007638 (FCT Ref. UID/AMB/50017), financed by national funds through the FCT/MEC and when appropriate co-financed by FEDER under the PT2020 Partnership Agreement. It was also 
supported by the Integrated Programme of SR\&TD "SusPhotoSolutions Soluções Fotovoltaicas Sustentáveis" (reference CENTRO-01-0145-FEDER000005), co-funded by Centro 2020 program, Portugal 2020, European Union, through the European Regional Development Fund. The authors are also grateful for the national fund through the Portuguese Foundation for Science and Technology (FCT) for the doctoral grant SFRH/BD/101683/2014 of F.A. Vicente and SFRH/BD/102915/2014 of J.H.P.M. Santos. S.P.M. Ventura and Ana C. R. V. Dias acknowledges FCT for the contracts IF/00402/2015 and IF/00587/2013, respectively.

\section{Funding}

Fundação para a Ciência e a Tecnologia. The financial support is divided in the PhD grants (SFRH/BD/101683/2014, SFRH/BD/102915/2014) and IF contracts IF/00402/2015 and IF/00587/2013, national Portuguese project (CENTRO-01-0145-FEDER-000005) that was financing the experimental development of the work, and projects which are financing the Associate Laboratories (CICECO and CESAM) responsible for the maintenance of the laboratory infrastructure used in the development of this work (CICECO - POCI-01-0145-FEDER-007679 (FCT Ref. UID/CTM/50011/ 2013), and CESAM - POCI-01-0145-FEDER-007638 (FCT Ref. UID/AMB/50017).

\section{Availability of data and materials}

Please contact author for data requests.

\section{Authors' contributions}

FAV, JHPMS, IMMP developed experimentally the work related with the development of the process, CVMG and ACRVD developed the environmental evaluation, JAPC and SPMV supervised the experimental work and worked on the preparation of the manuscript. All authors read and approved the final manuscript.

\section{Ethics approval and consent to participate}

not applicable.

\section{Consent for publication}

not applicable.

\section{Competing interests}

The authors declare that they have no competing interests.

\section{Publisher's Note}

Springer Nature remains neutral with regard to jurisdictional claims in published maps and institutional affiliations.

\section{Author details}

'Departamento de Química, CICECO, Universidade de Aveiro, Aveiro, Portugal. ${ }^{2}$ Department of Environment and Planning, CESAM - Centre for Environmental and Marine Studies, University of Aveiro, 3810-193 Aveiro, Portugal.

Received: 18 October 2018 Accepted: 2 January 2019

Published online: 30 January 2019

\section{References}

1. Shukla AA, Etzel SG MR. Process Scale Bioseparations for the Biopharmaceutical Industry. Boca Raton: CRC Press; 2006.

2. Berg JM, Tymoczko JL, Stryer L. Biochemistry:: section 4.1 the purification of proteins is an essential first step in understanding their function. 5th Editio. New York: WH Freeman; 2002.

3. Ventura SPM, Nobre BP, Ertekin F, Hayes M, Garciá-Vaquero M, Vieira F, et al. Extraction of value-added compounds from microalgae. In: MicroalgaeBased Biofuels and Bioproducts. Amsterdam: Elsevier; 2018. p. 461-83.

4. Balina K, Romagnoli F, Blumberga D. Seaweed biorefinery concept for sustainable use of marine resources. Energy Procedia. 2017;128:504-11. https://doi.org/10.1016/j.egypro.2017.09.067.

5. Asenjo JA, Andrews BA. Protein purification using chromatography: selection of type, modelling and optimization of operating conditions. J Mol Recognit An Interdiscip J. 2009;22:65-76.

6. Asenjo JA, Andrews BA. Aqueous two-phase systems for protein separation: A perspective. J Chromatogr A. 2011;1218:8826-35. https://doi.org/10.1016/j. chroma.2011.06.051.
7. Wan Y, Cui Z, Ghosh R. Fractionation of proteins using ultrafiltration: developments and challenges. Dev Chem Eng Miner Process. 2008;13(1-2): 121-36. https://doi.org/10.1002/apj.5500130112.

8. Cui Z. Protein separation using ultrafiltration - an example of multi-scale complex systems. China Particuology. 2005;3:343-8. https://doi.org/10.1016/ S1672-2515(07)60213-9.

9. Zittle CA, DellaMonica ES. Separation of proteins by gradient solvent extraction of a protein precipitate. Arch Biochem Biophys. 1955;58:31-6. https://doi.org/10.1016/0003-9861(55)90090-4

10. $\mathrm{Yu} \mathrm{H}$, Ito Y. Preparative separation of proteins using centrifugal precipitation chromatography based on solubility in ammonium sulfate solution. Prep Biochem Biotechnol. 2004;34:1-12.

11. Yau YK, Ooi CW, Ng E-P, Lan JC-W, Ling TC, Show PL. Current applications of different type of aqueous two-phase systems. Bioresour Bioprocess. 2015: 2:49. https://doi.org/10.1186/s40643-015-0078-0.

12. Molino JVD, Viana Marques Dde A, Júnior AP, Mazzola PG, MSV G. Different types of aqueous two-phase systems for biomolecule and bioparticle extraction and purification. Biotechnol Prog. 2013;29:1343-53. https://doi. org/10.1002/btpr.1792.

13. Ventura SPM, Silva FA E, Quental MV, Mondal D, Freire MG, JAP C. IonicLiquid-Mediated Extraction and Separation Processes for Bioactive Compounds: Past, Present, and Future Trends. Chem Rev. 2017;117:69847052. https://doi.org/10.1021/acs.chemrev.6b00550.

14. Iqbal M, Tao Y, Xie S, Zhu Y, Chen D, Wang X, et al. Aqueous two-phase system (ATPS): an overview and advances in its applications. Biol Proced Online. 2016;18:18. https://doi.org/10.1186/s12575-016-0048-8

15. Alexandridis P. Poly (ethylene oxide)/poly (propylene oxide) block copolymer surfactants. Curr Opin Colloid Interface Sci. 1997;2:478-89.

16. Persson J, Nyström L, Ageland $H$, Tjerneld F. Purification of recombinant and human apolipoprotein A-1 using surfactant micelles in aqueous twophase systems: recycling of thermoseparating polymer and surfactant with temperature-induced phase separation. Biotechnol Bioeng. 2000;65: 371-81. https://doi.org/10.1002/(SICI)1097-0290(19991120)65:4<371::AIDBIT1>3.0.CO;2-P

17. Merchuk JC, Andrews BA, Asenjo JA. Aqueous two-phase systems for protein separation. J Chromatogr B Biomed Sci Appl. 1998;711:285-93.

18. Chakraborty A, Sen K. Impact of $\mathrm{pH}$ and temperature on phase diagrams of different aqueous biphasic systems. J Chromatogr A. 2016;1433:41-55.

19. Shahriari S, Neves CMSS, Freire MG, Coutinho JAP. Role of the Hofmeister series in the formation of ionic-liquid-based. J Phys Chem B. 2012;116:7252-8

20. Vicente FA, Cardoso IS, Sintra TE, Lemus J, Marques EF, Ventura SPM, et al. Impact of surface active ionic liquids on the cloud points of nonionic surfactants and the formation of aqueous micellar two-phase systems. J Phys Chem B. 2017;121:8742-55. https://doi.org/10.1021/acs.jpcb.7b02972.

21. Vicente FA, Malpiedi LP, e Silva FA, Pessoa A Jr, JAP C, SPM V. Design of novel aqueous micellar two-phase systems using ionic liquids as cosurfactants for the selective extraction of (bio) molecules. Sep Purif Technol. 2014;135:259-67.

22. Liu CL, Nikas YJ, Blankschtein D. Novel bioseparations using two-phase aqueous micellar systems. Biotechnol Bioeng. 1996;52:185-92. https://doi. org/10.1002/(SICI)1097-0290(19961020)52:2<185::AID-BIT1>3.0.CO;2-M.

23. Safety Assessment of Poloxamers 101, 105, 108, 122, 123, 124, 181, 182, 183, $184,185,188,212,215,217,231,234,235,237,238,282,284,288,331,333$, $334,335,338,401,402,403$, and 407, Poloxamer 105 Benzoate, and Poloxamer 182 Dibenzoate as Use. Int J Toxicol. 2008;27(2_suppl):93-128. https://doi.org/10.1080/10915810802244595.

24. Ventura SPM, Neves CMSS, Freire MG, Marrucho IM, Oliveira J, Coutinho JAP. Evaluation of anion influence on the formation and extraction capacity of ionic-liquid-based aqueous biphasic systems. J Phys Chem B. 2009;113: 9304-10. https://doi.org/10.1021/jp903286d.

25. Louros CLS, Cláudio AFM, Neves CMSS, Freire MG, Marrucho IM, Pauly J, et al. Extraction of biomolecules using Phosphonium-based ionic liquids + K3PO4 aqueous biphasic systems. Int J Mol Sci. 2010;11:1777-91 http:// www.mdpi.com/journal/ijms. https://doi.org/10.3390/ijms1 1041777.

26. Blankschtein D, Thurston GM, Benedek GB. Phenomenological theory of equilibrium thermodynamic properties and phase separation of micellar solutions. J Chem Phys. 1986:85:7268-88.

27. Ecoinvent, http://www.ecoinvent.org. 2018.

28. Lemos D, Dias AC, Gabarrell X, Arroja L. Environmental assessment of an urban water system. J Clean Prod. 2013;54:157-65. 
29. Sigma. Sigma Aldrich Company.

30. Campbell BWH, Orme-johnson WH, Burris RH. A Comparison of the Physical and Chemical Properties of Four Cytochromes c from Azotobacter vinelandii. Biochem J. 1973;135:617-30.

31. Hofland GW, Van Es M, Van Der Wielen LAM, Witkamp GJ. Isoelectric precipitation of casein using high-pressure CO2. Ind Eng Chem Res. 1999;38: 4919-27.

32. Smith ERB. The effect of variations in ionic strength on the apparent isoelectric point of egg albumin. J Biol Chem. 1935;108:187-94.

33. Kawaguchi $\mathrm{H}$, Noda $\mathrm{H}$. Thermal denaturation of cytochromes $\mathrm{c}$ of horse cow, and Candida krusei in aqueous guanidine hydrochloride. J Biochem. 1977:81:1307-17.

34. Secades P, Guijarro JA. Purification and characterization of an extracellular protease from the fish pathogen Yersinia ruckeri and effect of culture condition on production. Appl Environ Microbiol. 1999:65:3969-75.

35. Hu HY, Du HN. Alpha-to-beta structural transformation of ovalbumin: heat and pH effects. J Protein Chem. 2000;19:177-83.

Ready to submit your research? Choose BMC and benefit from:

- fast, convenient online submission

- thorough peer review by experienced researchers in your field

- rapid publication on acceptance

- support for research data, including large and complex data types

- gold Open Access which fosters wider collaboration and increased citations

- maximum visibility for your research: over $100 \mathrm{M}$ website views per year

At BMC, research is always in progress.

Learn more biomedcentral.com/submissions 